\title{
Les écrits sur l'art d'André Malraux, Sous la direction de Jeanyves Guérin et Julien Dieudonné
}

\section{Emanuele Kanceff}

\section{Q OpenEdition}

1 Journals

\section{Edizione digitale}

URL: https://journals.openedition.org/studifrancesi/26826

DOI: 10.4000/studifrancesi.26826

ISSN: 2421-5856

\section{Editore}

Rosenberg \& Sellier

\section{Edizione cartacea}

Data di pubblicazione: 1 avril 2007

Paginazione: 214

ISSN: 0039-2944

\section{Notizia bibliografica digitale}

Emanuele Kanceff, «Les écrits sur l'art d'André Malraux, Sous la direction de Jeanyves Guérin et Julien Dieudonné», Studi Francesi [Online], 151 (LI | I) | 2007, online dal 30 novembre 2015, consultato il 23 novembre 2021. URL: http://journals.openedition.org/studifrancesi/26826 ; DOI: https://doi.org/ 10.4000/studifrancesi.26826

Questo documento è stato generato automaticamente il 23 novembre 2021.

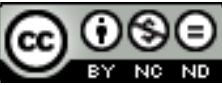

Studi Francesi è distribuita con Licenza Creative Commons Attribuzione - Non commerciale - Non opere derivate 4.0 Internazionale. 


\title{
Les écrits sur l'art d'André Malraux, Sous la direction de Jeanyves Guérin et Julien Dieudonné
}

\author{
Emanuele Kanceff
}

\section{NOTIZIA}

AA. VV., Les écrits sur l'art d'André Malraux, Sous la direction de Jeanyves GUÉRIN et Julien DIEUDONNÉ, Paris, Presses de la Sorbonne Nouvelle, 2006, pp. 189.

1 Gli studi raccolti in questo volume sono dedicati agli scritti sull'arte di Malraux, ormai pubblicati nell'edizione Pléiade, sia dal punto di vista teorico che da quello critico, oltre naturalmente a quello letterario. Dal confronto che gli studiosi istituiscono con altri scritti contemporanei e dall'analisi che viene messa in opera si evidenzia molto bene la loro forza ideale e la loro originalità.

Il centenario della nascita e l'ingresso al Panthéon sembrano aver allontanato ancora di più lo scrittore da quella presenza viva che gli avevano conferito i suoi grandi romanzi e offuscato il suo impegno sociale. In realtà, in lui coesistono due scrittori che non possono fare a meno l'uno dell'altro e, come dice Guérin, «pour écrire La Condition humaine il faut avoir une appréhension de l'art. Pour écrire Les Voix du silence il faut avoir été romancier». E certamente l'immagine di un romanziere che lascia la letteratura per diventare critico d'arte non corrisponde al vero per Malraux, se si pensa che il suo primo saggio di critica d'arte risale all'età di 21 anni e l'ultimo a poche settimane prima della morte. Ma gli ha nuociuto la dispersione di questi scritti a lungo relegati nel settore dei libri d'arte. In questi saggi, sulla poetica dell'enigma, sul confronto con Ponge davanti a Fautrier, su stile e astrazione nelle Voix du silence, sul "Malraux metteur en page", sui riferimenti cristiani della sua scrittura d'arte, sul canto metamorfico del Musée imaginaire, sullo statuto aporetico dei suoi scritti sull'arte, sul confronto con Picon e con Blanchot, si 
evidenzia tutta l'importanza e la letterarietà di un romanziere che ha saputo dire sull'arte parole incancellabili. 